\title{
Pitaya-Like Sulfur Electrodes by Chemically Anchored Polyaniline Shell for Lithium-Sulfur Batteries
}

\author{
Yan Wang ${ }^{1, *}$, Wenxuan Wang $^{2}$ \\ ${ }^{1}$ School of Information and Electronic Engineering, Hunan University of Science and Technology, \\ Hunan 411201, China \\ ${ }^{2}$ School of Materials Science and Engineering, Xiangtan University, Hunan 411105, China \\ *E-mail: ywang8@hnust.edu.cn
}

doi: $10.20964 / 2017.12 .11$

Received: 9 June 2016 / Accepted: 16 September 2017 / Published: 12 November 2017

Lithium-sulfur batteries are an attractive technology due to the light weight and low cost of sulfur, and a high theoretical specific capacity and specific energy compared to current lithium-ion batteries. However, a rapid capacity fade may occur which can be attributed mainly to polysulfide dissolution and volume expansion. To trap the polysulfides in the electrode of lithium-sulfur batteries and improve the electrochemical performances, we prepared a core-shell structure of polymer-coated sulfur cathode. By a simple two-step liquid phase reaction, a core-shell structural pitaya-like $\mathrm{S} / \mathrm{SiO}_{2} @$ polyaniline (SSP) was first reported, which is expected to be catalytic for chemical reactions and able to adsorb lithium polysulphides. The results show that the SSP composites exhibited a high specific capacity and good cycling stability due to the role of complementary advantages of both polyaniline shell and $\mathrm{SiO}_{2}$ particles for lithium-sulfur batteries. The SSP cathode delivered an initial specific discharge capacity of $850 \mathrm{~mA} \mathrm{~h} \mathrm{~g}^{-1}$ and maintained $500 \mathrm{~mA} \mathrm{~h} \mathrm{~g}$ after 230 cycles at $0.5 \mathrm{C}$. The improvements of electrochemical performances may be attributed to the unique hybrid nanostructure of SSP and good dispersion of $\mathrm{SiO}_{2}$ particles in sulfur.

Keywords: Polyaniline; Core-shell; Cathodes; Lithium-sulfur batteries

\section{FULL TEXT}

(C) 2017 The Authors. Published by ESG (www.electrochemsci.org). This article is an open access article distributed under the terms and conditions of the Creative Commons Attribution license (http://creativecommons.org/licenses/by/4.0/). 